\title{
Effect of omega-3 long-chain polyunsaturated fatty acid supplementation on heart rate: a meta-analysis of randomized controlled trials
}

\author{
Khemayanto Hidayat ${ }^{1} \cdot$ Jing Yang ${ }^{1} \cdot$ Zheng Zhang $^{1} \cdot$ Guo-Chong Chen ${ }^{1} \cdot$ Li-Qiang Qin ${ }^{1} \cdot$ Manfred Eggersdorfer $^{2}$. \\ Weiguo Zhang ${ }^{3}$
}

Received: 24 July 2017 / Revised: 6 October 2017 / Accepted: 17 October 2017 / Published online: 28 December 2017

(c) The Author(s) 2018. This article is published with open access

\begin{abstract}
Background Elevated resting heart rate (HR) has emerged as a new risk factor for all-cause and cardiovascular mortality. The effect of marine-derived omega-3 long-chain polyunsaturated fatty acid ( $n-3$ LCPUFAs) supplementation on HR was investigated as an outcome in many clinical trials. The present study was to provide an updated meta-analysis on the HRslowing effect of $n-3$ LCPUFAs, and to differentiate the chronotropic effect between eicosapentaenoic acid (EPA) and docosahexaenoic acid (DHA).

Methods PubMed and Cochrane databases were searched for relevant articles examining the effects of $n-3$ PUFAs on HR through May 2017. A random-effects model was used to generate the pooled effect sizes and $95 \%$ confidence intervals (CIs). The pooled effect sizes were presented as weighted mean differences (WMDs).

Results A total of 51 randomized controlled trials (RCTs) with approximately 3000 participants were included in this metaanalysis. Compared to placebo, $\mathrm{n}-3$ PUFA supplementation mildly but significantly reduced HR $(-2.23 \mathrm{bpm}$; $95 \%$ CI: $-3.07,-1.40 \mathrm{bpm})$. Moderate evidence of heterogeneity was observed among included trials $\left(I^{2}=49.1 \%, P\right.$ heterogeneity $<0.001)$. When DHA and EPA were separately administered, modest HR reduction was observed in trials that supplemented with DHA ( $-2.47 \mathrm{bpm}$; 95\% CI: $-3.47,-1.46 \mathrm{bpm})$, but not in trials with EPA.

Conclusions The present meta-analysis provides strong clinical evidence demonstrating the effect of heart rate reduction by n-3 LCPUFA supplementation. When DHA or EPA administered alone, heart rate was slowed by DHA rather than by EPA.
\end{abstract}

Electronic supplementary material The online version of this article (https://doi.org/10.1038/s41430-017-0052-3) contains supplementary material, which is available to authorized users.

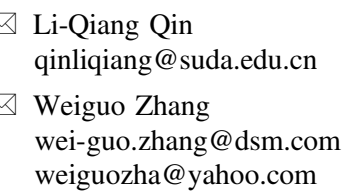

1 Department of Nutrition and Food Hygiene, School of Public Health, Soochow University, Suzhou 215123, China

2 DSM Nutritional Products, Human Nutrition and Health, 4303 Kaiseraugst, Switzerland

3 DSM Nutritional Products, Human Nutrition and Health, Beijing 100020, China

\section{Introduction}

The potential cardioprotective effects of marine-derived omega-3 long-chain polyunsaturated fatty acids ( $n-3$ LCPUFAs) and fish intake have been investigated in numerous studies $[1,2]$. Findings from a prospective study of male physicians without a history of pre-existing cardiovascular disease suggest that those who consumed fish at least once per week had a lower risk of sudden cardiac death (SCD) [3]. Moreover, baseline blood levels of $n-3$ LCPUFAs were also inversely associated with SCD in this population [4]. Similarly, n-3 LCPUFAs from fatty fish consumption or fish oil supplementation have been shown to lower the risk of SCD in several secondary prevention studies [4-7]. Although the exact physiologic mechanisms underlying this preventive effect of $n-3$ LCPUFAs on SCD remain unclear, it has been suggested that $n-3$ LCPUFAs may exert its protective effect on SCD by reducing heart rate (HR) [8]. Elevated resting HR is a potential risk factor 
for cardiovascular morbidity and mortality [9-12], particularly SCD. Therefore, any agent with HR-reducing effect and relatively no side effect may serve as a valuable candidate in SCD prevention. To this end, the effect of $n-3$ LCPUFA supplementation on HR has been investigated in a large number of randomized controlled trials (RCTs) [1363], with most of the RCTs showing HR reduction compared to placebo. In 2005, Mozaffarian et al. [64] published a meta-analysis including 30 RCTs and reported that $n-3$ PUFA supplementation reduced HR by 1.6 beats per minute (bpm). Although 21 additional RCTs [43-63] have been published since then, no updated meta-analysis has been performed. Furthermore, several RCTs have separately investigated the effects of two major $n-3$ LCPUFAs, namely eicosapentaenoic acid (EPA) and docosahexaenoic acid (DHA), on HR [30, 31, 33-36, 40, 45, 54, 56]. However, whether EPA or DHA similarly results in HR reduction has not been systematically analyzed.

In order to provide updated evidence on the effect of $n$ -3 LCPUFAs on HR reduction and to differentiate the chronotropic effect between EPA and DHA when they were separately administered, we carried out this meta-analysis and systematic review.

\section{Methods}

\section{Search strategy}

This present meta-analysis was planned, conducted, and reported in accordance with the preferred reporting items for systematic reviews and meta-analyses guidelines (PRISMA) [65]. PubMed and Cochrane databases were searched for relevant articles examining the effects of $n-3$ LCPUFAs on HR through May 2017. The following search terms were employed to identify relevant articles in the databases: (omega 3 fatty acids OR omega 3 OR polyunsaturated fatty acids OR PUFA OR fish oil OR marine oil OR eicosapentaenoic acid OR EPA OR docosahexaenoic acid OR DHA) AND (heart rate OR HR OR pulse). The search strategy had no restriction on language, publication date, or article type. The reference lists of the previous metaanalyses were reviewed to complement the database searches. Additionally, we also attempt to contact the authors of the original studies for unreported HR data.

\section{Selection and inclusion of RCTs}

The studies eligible for inclusion in this meta-analysis had to meet the following inclusion criteria: (1) RCTs lasted at least 2 weeks; (2) one or more intervention groups received n-3 LCPUFA supplementation (i.e., fish oil (EPA plus DHA), purified EPA, purified DHA) or food containing $n$
-3 LCPUFAs (i.e., fatty fish) and being compared with placebo; (3) trials reported effects on HR; and (4) the mean age of participants was $\geq 18$ years.

\section{Data extraction and assessment of bias}

Using a standardized data collection form, the following study characteristics were abstracted from each study: (1) first author's last name, year of publication; (2) participant characteristics including the mean age, sex, and health status; (3) trial characteristics including the trial design, number of participants in intervention or control groups, total dose of EPA plus DHA, ratio of EPA to DHA, trial duration, type of control, dropout rate, and blinding; and (4) methods of HR assessment. Cochrane tool for assessing the risk of bias was used to evaluate the risk of bias among the included studies (Supplementary Table S1) [66]. Two authors (KH and JY) independently performed the database search, data extraction, and quality assessment. Any discrepancies regarding inclusion were resolved by group discussion.

\section{Statistical analysis}

Omega-3 PUFA was considered as the intervention arm in this meta-analysis. If the multi-arm interventions included multiple doses of $n-3$ LCPUFAs, we included those with the highest dose in the meta-analysis. The mean changes of HR in both intervention and control groups were reported as differences between mean values at baseline and final. The standard deviations (SDs) for changes from baseline in each group were obtained from each trial. If not reported, the standard errors (SEs), confidence intervals (CIs), and $P$ values were all converted to SDs using a standard formula [66]. If only SDs for the baseline and final values were provided, we computed SDs for net changes using the method proposed by Follmann et al. [67] in which a correlation coefficient of 0.5 was assumed. The degree of heterogeneity across trials was assessed using $Q$ and $I^{2}$ statistics. For the $Q$ statistic, $P<0.1$ was considered statistically significant; and for the $I^{2}$ statistic, the following conventional cut-off points were used: $<25 \%$ (low heterogeneity), $25-75 \%$ (moderate heterogeneity), and $>75 \%$ (severe heterogeneity). Potential publication bias was assessed using both Begg's rank correlation test and Egger's linear regression [68]. If the publication bias was detected, the trim and fill method was performed to correct the bias [69]. A random-effects model was used to generate the pooled effect sizes and 95\% CIs [70]. The pooled effect sizes were presented as weighted mean differences (WMDs). To explore the possible influences of trial and participant characteristics on the pooled effect sizes, predefined subgroup and meta-regression analyses were 
performed according to the trial design (parallel vs. crossover), mean age of participants ( $<55 \mathrm{vs.} \geq 55$ ), health status of participants (generally healthy vs. chronic condition), baseline HR ( $<69$ vs. $\geq 69$ ), total dose of EPA plus DHA ( $<3.5$ vs. $\geq 3.5 \mathrm{~g} /$ day $)$, individual $\mathrm{n}-3$ PUFA supplementation (EPA vs. DHA), EPA to DHA ratio ( $<1.5$ vs. $>1.5$ ), methods of HR measurement (single vs. multiple average vs. ambulatory/continuous), and type of control (olive oil vs. other). In addition, sensitivity analyses were performed to investigate the influence of a single trial on the overall effect estimated by omitting one trial in each turn. All analyses were performed using STATA version 11.0 (StataCorp, College Station, TX, USA). A $P$-value $<0.05$ was considered to be statistically significant, unless otherwise specified.

\section{Results}

\section{Trial characteristics}

A flowchart of study selection, including reasons for exclusion, is presented in Fig. 1. Totally, 51 RCTs were eligible for this meta-analysis, in which 4 trials had two separated intervention groups and approximately 3000 subjects participated. The trials were published between 1988 and 2016. In term of the trial classification, 11 trials were crossover designed and 40 parallel designed; 3 trials were with single-blind treatment, 2 open-labeled, and the remaining double blind; 24 intervention groups were conducted in healthy participants, whereas the other 32 in

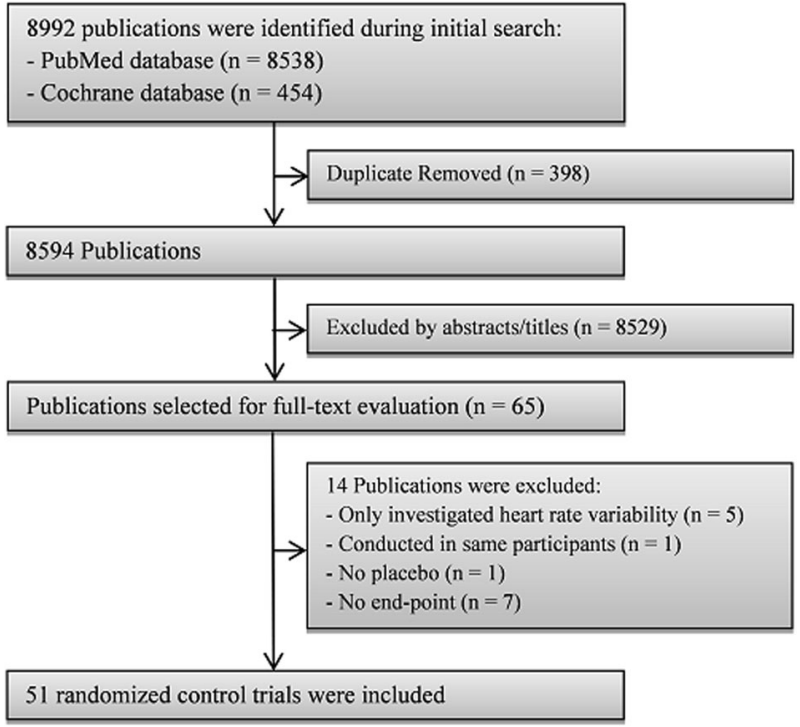

Fig. 1 Flowchart of study selection participants with at least one chronic condition, such as coronary artery disease, renal failure, hypertension, hyperlipidemia, type 2 diabetes mellitus, frequent premature ventricular contraction, epilepsy, psoriatic arthritis, severely accident injured, and age-related cognitive decline; 19 trials were conducted exclusively in men, 2 in women, and the remaining included both sexes; the duration of trials ranged from 2 weeks to 1 year; the mean age of participants ranged from 22.45 to 70 years; HR of the participants in almost all trials was within the normal range (i.e., $60-100 \mathrm{bpm}$ ). The dose of EPA plus DHA ranged from 0.5 to $15 \mathrm{~g} / \mathrm{d}$, with the ratio of EPA to DHA from 0.1 to 4.9. Ten studies separately examined the differential effects of EPA and DHA. Placebo was chosen from corn oil, olive oil, safflower oil, soybean oil, sunflower oil, or mixed oil for control groups. The single HR measurement was used in 18 , the average of multiple HR measurement in 23 , and the average of ambulatory or continuous monitoring in 25 intervention trials. Most of the trials reported no significant side effect of LCPUFA.

\section{Effect of $n-3$ PUFAs on HR}

The net changes in HR between the intervention and control groups ranged from 0 to $10 \mathrm{bpm}$. Compared to placebo, $\mathrm{n}$ -3 LCPUFA supplementation mildly but significantly reduced HR ( $-2.23 \mathrm{bpm}$; 95\% CI: $-3.07,-1.40 \mathrm{bpm}$; Fig. $2)$. Moderate evidence of heterogeneity was observed among included trials $\left(I^{2}=49.1 \%, P\right.$ heterogeneity $<$ 0.001). Neither Begg's rank correlation nor Egger's linear test observed the presence of publication bias $(P$ Begg's $=$ $0.591, P$ Egger's $=0.450$; Table 1 ).

\section{Subgroup and sensitivity analyses}

The results of subgroup analyses according to mean age of participants, the health status of participants, baseline HR, total dose of EPA plus DHA, individual $n-3$ PUFA supplementation, EPA to DHA ratio, methods of HR measurement, type of control, and Jadad score are presented in Table 2. The effect of $n-3$ LCPUFA supplementation on HR appeared to be influenced by specific n-3 LCPUFA supplementation $(P$ meta-regression $<0.01)$. When comparing the separate effects of EPA and DHA supplementations on HR, modest HR reduction was observed in trials that supplemented with DHA $(-2.47 \mathrm{bpm}$; 95\% CI: $-3.47,-1.46$ bpm; Fig. 3), whereas statistically significant effect was not observed with EPA supplementation (1.19 bpm; 95\% CI: $-0.30,2.67$ bpm; Fig. 3). The sensitivity analysis restricted to double-blind trials, and by using different values of the correlation coefficient $R(0.25$ and 0.75$)$ did not materially alter the observed results. Moreover, the sensitivity analysis by omitting one trial in each turn 


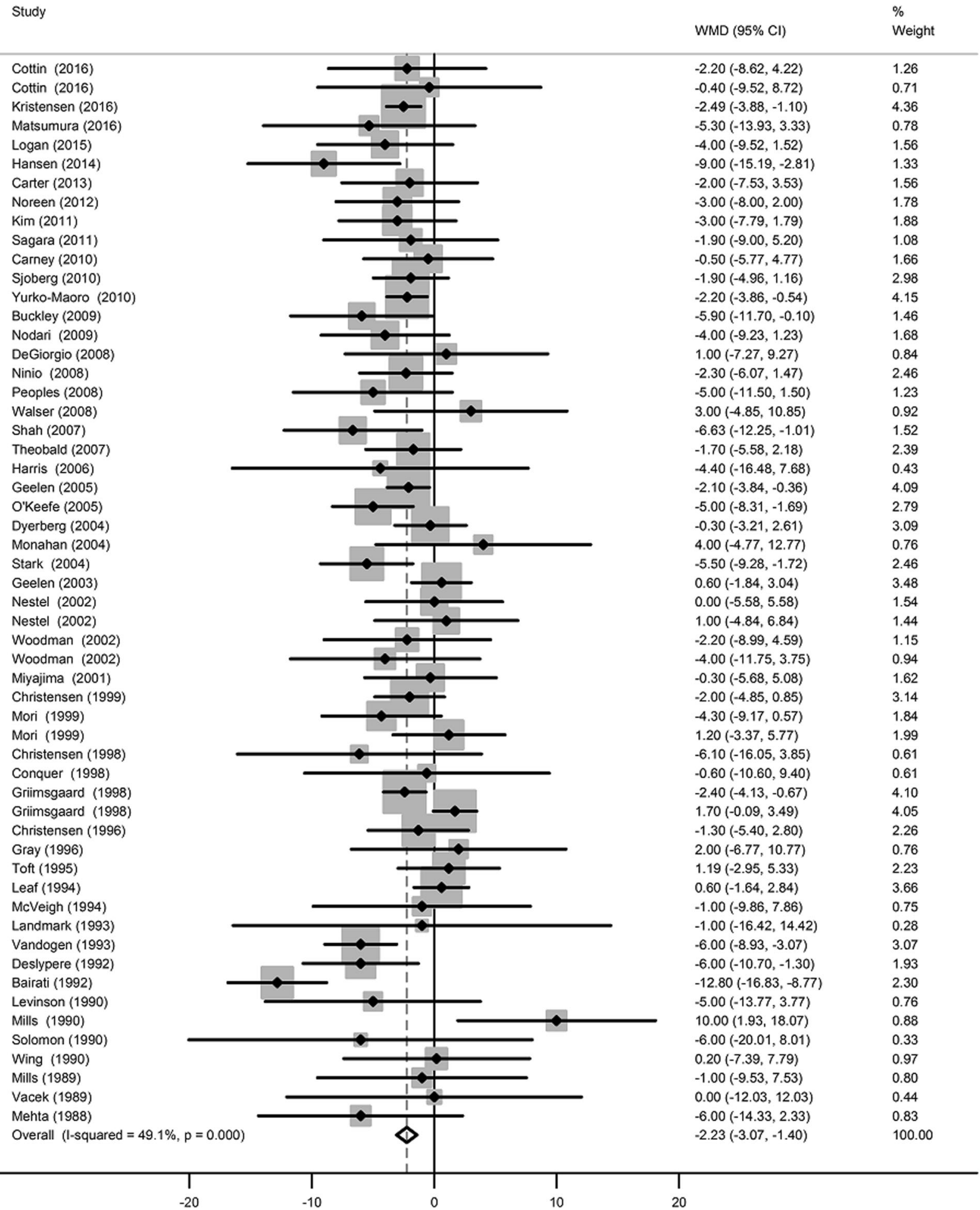

Fig. 2 Forest plot of the change in heart rate resulting from n-3 PUFA supplementation

revealed that the overall findings were free from the influence of a single study. In addition, the overall results remained statistically significant $(-2.24 \mathrm{bpm} ; 95 \% \mathrm{CI}$ : $-3.08,-1.39 \mathrm{bpm}$ ) after omission of trials with duration less than 6 weeks.

\section{The risk of bias}

The risk of bias in included studies is presented in supplementary table $\mathrm{S} 1$. In these trials, $17.6 \%$ presented adequate random sequence generation, $88 \%$ reported allocation 


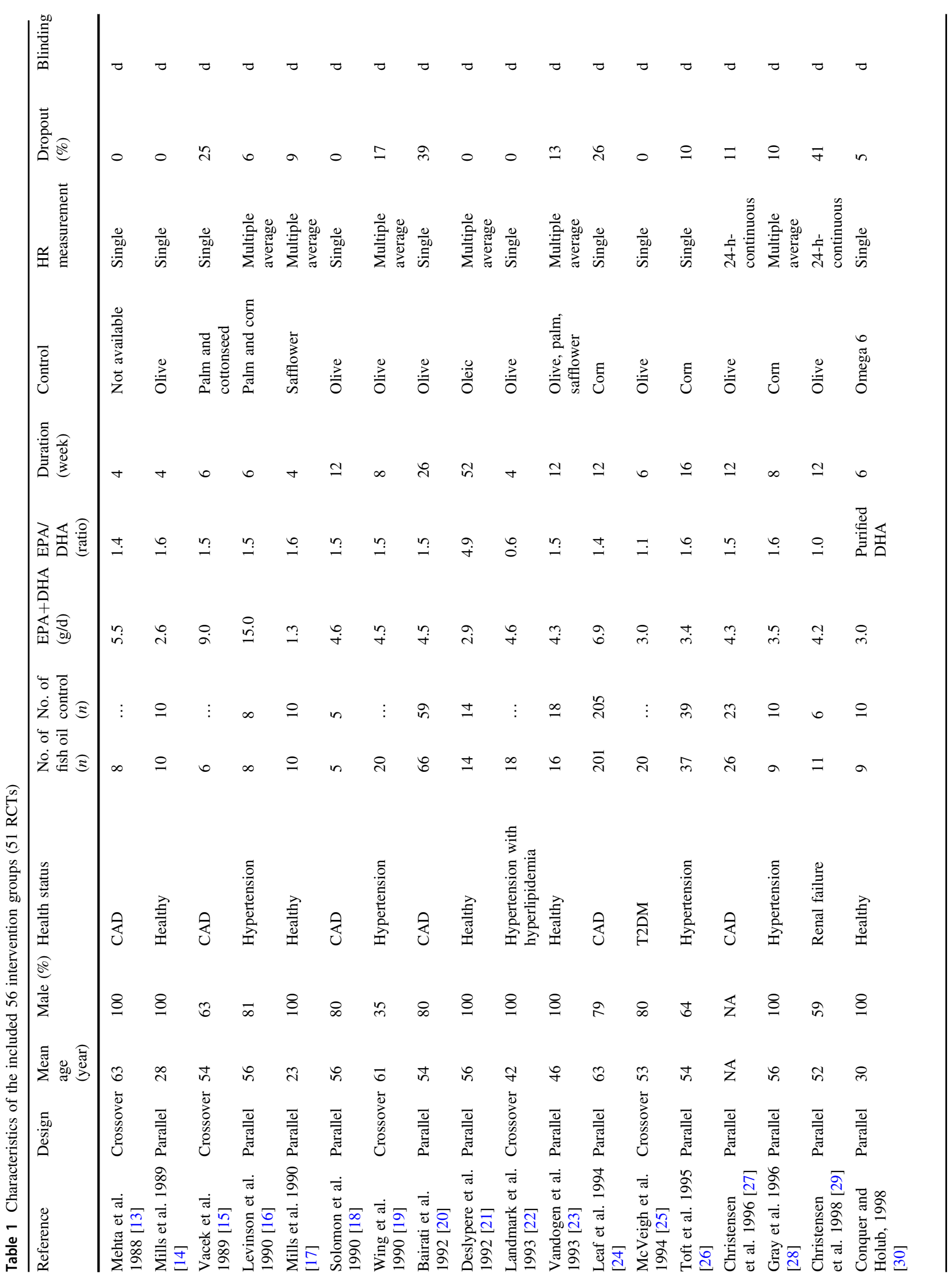




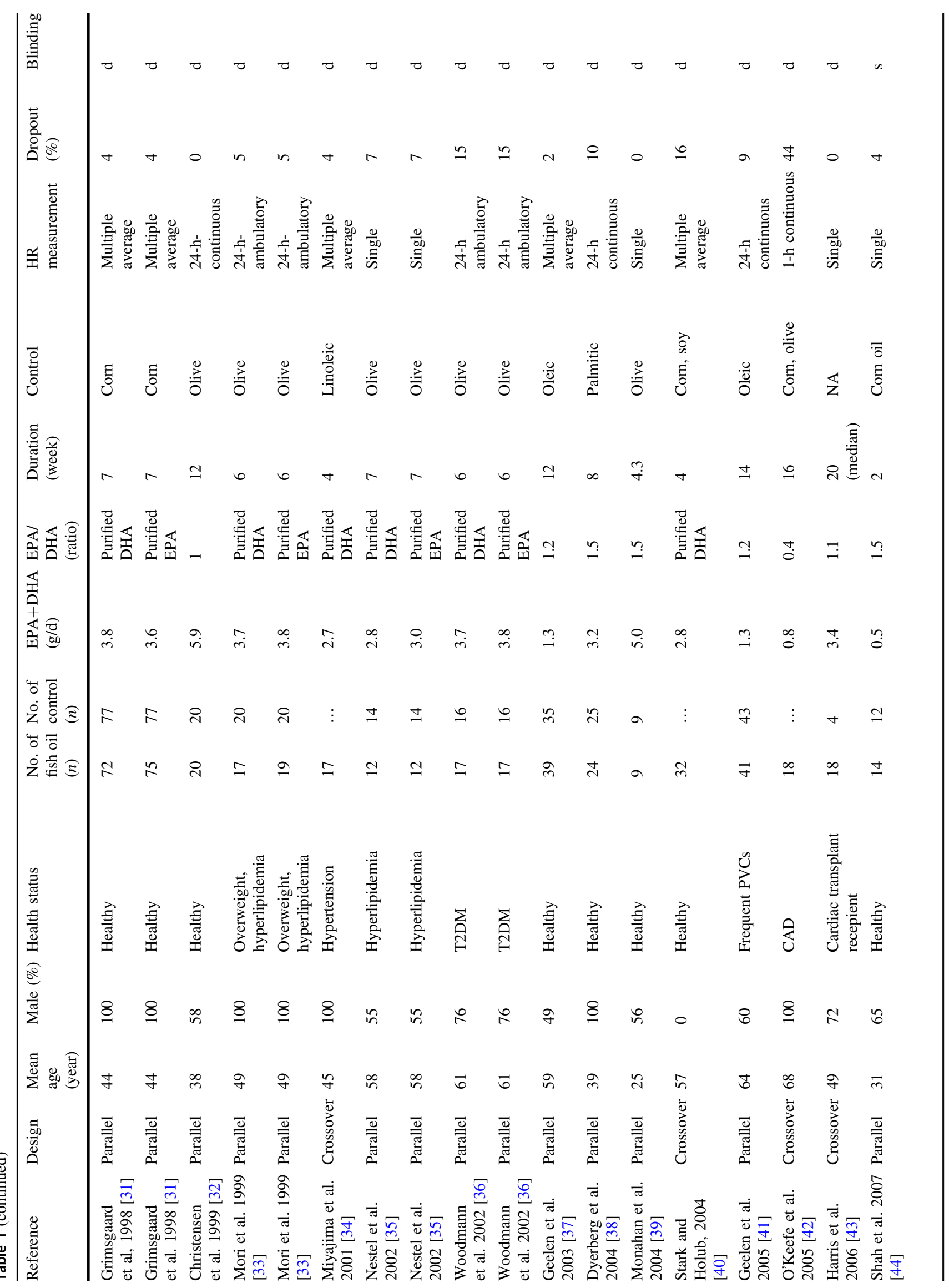




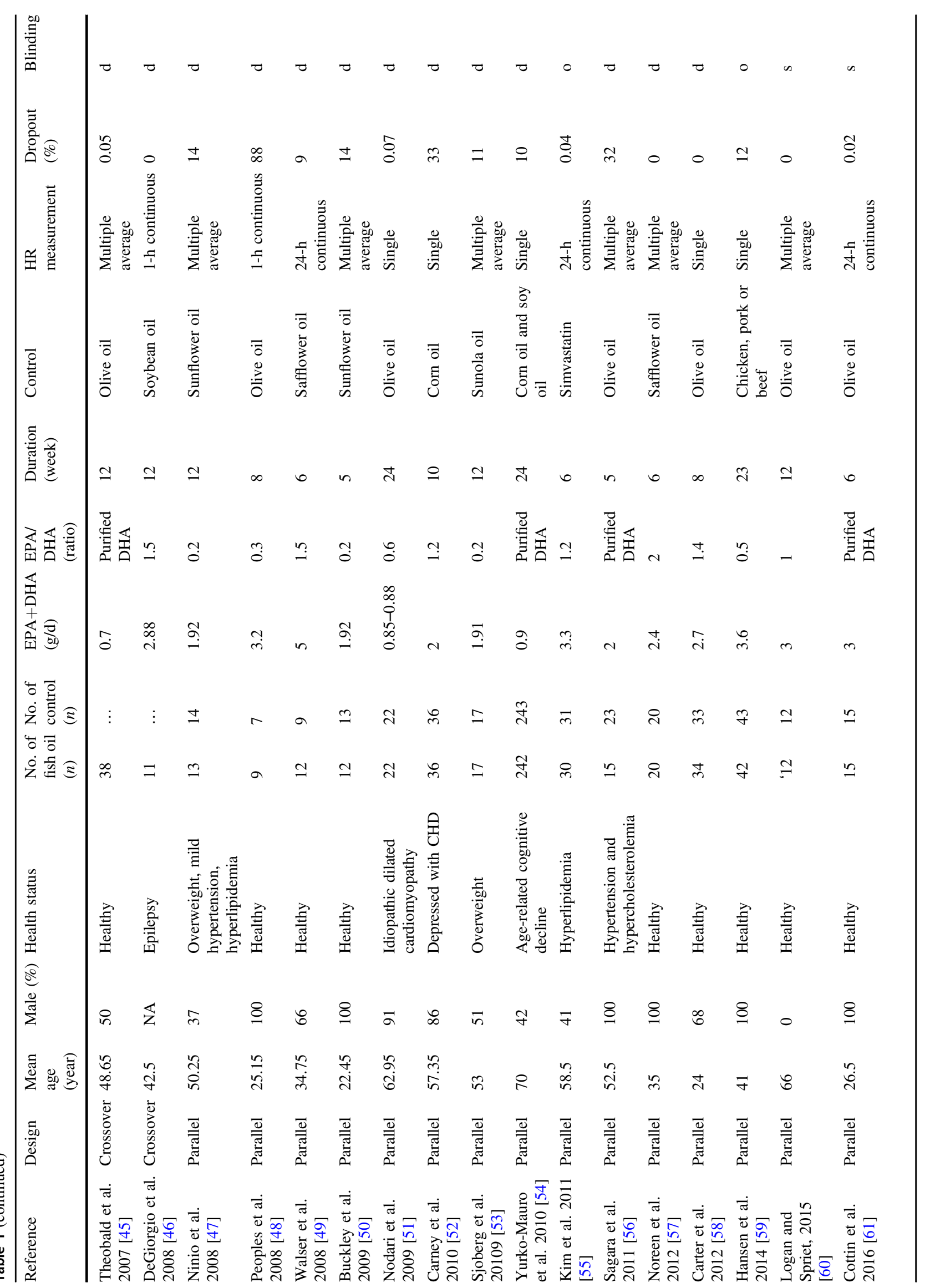


concealment, $88 \%$ had blinded participants and study investigators (7 of 10), 88\% had blinded assessment of outcomes, $100 \%$ had low risk of attrition bias, $84 \%$ had low risk of reporting bias, and $78 \%$ had low risk of other bias. In general, four studies were considered to be of poor quality, while the remaining studies were considered to be of fair or good quality.

\section{Discussion}

The novel major findings from the present meta-analysis are twofold. First, by pooling the results from 51 RCTs, our study provided the latest evidence that $n-3$ LCPUFA supplementation reduced HR compared to placebo $(-2.23$ bpm; 95\% CI: $-3.07,-1.40 \mathrm{bpm})$; Second, by pooling results from EPA and DHA administration trials separately, our study demonstrated that DHA rather than EPA reduced HR compared to placebo ( $-2.47 \mathrm{bpm}$ with DHA; $95 \% \mathrm{CI}$ : $-3.47,-1.46 \mathrm{bpm}$ ), thereby more ascribable to the negative chronotropic effect.

The effect of $n-3$ LCPUFA supplementation on HR was previously analyzed by Mozaffarian et al. [64] in 2005; however, it included only 30 RCTs with 1678 participants compared with 51 RCTs with approximately 3000 participants in our present meta-analysis. With more RCTs included than the previous one, this present meta-analysis provides more updated and comprehensive review of the current literature concerning the effect of $n-3$ LCPUFA supplementation on HR. The change in weight across trials was observed because of the significant difference in the total number of included trials. Compared to the previous meta-analysis, our findings were relatively more stable and less influenced by individual trials because a large number of additional trials were included. Moreover, our metaanalysis showed that the magnitude of HR reduction was somewhat greater than the previous meta-analysis $(-2.23$ bpm; 95\% CI: $-3.07,-1.40$ bpm vs. -1.55 bpm; 95\% CI: $-2.51,-0.59 \mathrm{bpm})$. Furthermore, the previous metaanalysis combined multiple doses of intervention (compared to the same control) in the same meta-analysis. This approach could be problematic due to a double or triple counting of the control group, and these effect sizes from a single study might not be independent of each other. In contrast, we only included the intervention group with the highest dose to avoid this issue. Besides, several studies suggested that EPA and DHA had differential effects on HR $[30,31,33-36,40,45,54,56]$, but the clarification on these issues has not been examined in the previous meta-analysis. Nonetheless, we further examine the effects of EPA and DHA supplementations on HR.

On the population level, $\mathrm{n}-3$ LCPUFAs and dietary fish intake have been reported to be associated with a greater 
Table 2 Subgroup analyses of the effect of $n-3$ PUFA supplementation on HR according to predefined study characteristics

\begin{tabular}{|c|c|c|c|}
\hline Characteristic & Intervention groups, $n$ & $\begin{array}{l}\text { Effect on HR }(95 \% \mathrm{CI}) \\
\text { bpm }\end{array}$ & $P$ meta-regression \\
\hline \multicolumn{4}{|l|}{ Design } \\
\hline Parallel & 45 & $-2.11(-3.06,-1.15)$ & \multirow[t]{2}{*}{0.53} \\
\hline Crossover & 11 & $-2.97(-4.30,-1.63)$ & \\
\hline \multicolumn{4}{|l|}{ Mean age, year } \\
\hline$<55$ & 35 & $-2.20(-3.50,-0.90)$ & \multirow[t]{2}{*}{0.91} \\
\hline$\geq 55$ & 21 & $-2.12(-3.02,-1.22)$ & \\
\hline \multicolumn{4}{|l|}{ Health status } \\
\hline Generally healthy & 24 & $-2.21(-3.58,-0.85)$ & \multirow[t]{2}{*}{0.93} \\
\hline Chronic condition & 32 & $-2.27(-3.31,-1.23)$ & \\
\hline \multicolumn{4}{|l|}{ Baseline HR, bpm } \\
\hline$<69$ & 26 & $-1.81(-3.20,-0.42)$ & \multirow[t]{2}{*}{0.34} \\
\hline$\geq 69$ & 30 & $-2.50(-3.26,-1.74)$ & \\
\hline \multicolumn{4}{|l|}{ EPA+DHA, g/d } \\
\hline$<3.5$ & 34 & $-2.10(-2.82,-1.39)$ & \multirow[t]{2}{*}{0.70} \\
\hline$\geq 3.5$ & 22 & $-2.55(-4.41,-0.70)$ & \\
\hline \multicolumn{4}{|c|}{ Individual $n-3$ supplementation } \\
\hline DHA & 10 & $-2.47(-3.47,-1.46)$ & \multirow[t]{2}{*}{$<0.01$} \\
\hline EPA & 6 & $1.19(-0.30,2.67)$ & \\
\hline \multicolumn{4}{|l|}{ EPA/DHA (ratio) } \\
\hline$<1.5$ & 21 & $-2.24(-3.25,-1.23)$ & \multirow[t]{2}{*}{0.72} \\
\hline$\geq 1.5$ & 19 & $-2.19(-4.23,-0.14)$ & \\
\hline \multicolumn{4}{|l|}{ HR measurement } \\
\hline Single & 18 & $-2.09(-3.70,-0.48)$ & \multirow{3}{*}{0.52} \\
\hline Multiple average & 23 & $-2.03(-3.37,-0.69)$ & \\
\hline Ambulatory/continuous & 15 & $-1.99(-3.01,-0.99)$ & \\
\hline \multicolumn{4}{|l|}{ Control } \\
\hline Olive oil & 25 & $-2.60(-3.92,-1.27)$ & \multirow[t]{2}{*}{0.37} \\
\hline Other & 29 & $-1.96(-3.06,-0.87)$ & \\
\hline
\end{tabular}

reduction in HR [71-73], which is approximated by $\mathrm{n}-3$ LCPUFA supplementation that reduced HR by $2.23 \mathrm{bpm}$ and DHA supplementation that reduced HR by 2.47 in this meta-analysis. It should also be further noted that the HR of the majority of participants included in this meta-analysis was within normal range-the state where reducing $\mathrm{HR}$ is conventionally not a medical indication [12]. At the population level however, such HR reduction may have significant public health implications, as a reduction of 3.2 bpm HR would roughly correspond to $7.5 \%$ lower risk of SCD [73]. Given the fact that both previous and present meta-analyses showed greater HR reduction trend in those with higher baseline HR, future trials may compare the effect of n-3 LCPUFA supplementation on different levels of baseline HR, particularly in those with tachycardia (resting HR > $100 \mathrm{bpm}$ ) or high-normal [12, 74].

The regulation of HR in humans involves multiple systems (e.g., cardiovascular, metabolic, endocrine, and autonomic nervous/neural systems) and their interactions. Aside from pharmacological drugs, lifestyle (e.g., physical fitness, psychological status, and diet or nutrition) and environment (e.g., noise and temperature) also modulates cardiac rhythm $[8,12,64]$. In vitro evidence showed that $n-3$ LCPUFAs directly modulated the functions of ion channels leading to reversible elevation in action potential threshold, lowering resting membrane potential and the duration of the refractory period, and finally resulting in reduction of membrane electrical excitability of cardiac myocytes [8, 12, 64]. Specifically, the inhibitory effect of $n-3$ LCPUFAs on funny channel current (i.e. $\mathrm{I}_{f}$ ), which lengthens spontaneous depolarization in cardiac pacemaker cells (i.e. sinoatrial node), is highly attributable to causing HR reduction [12, 64].

It is important to clarify the relative effects of EPA and DHA on various health outcomes in this era where $n-3$ LCPUFA supplements are available. The effects of individual components of $n-3$ LCPUFAs on HR remain poorly understood, as majority of the studies used the combination 


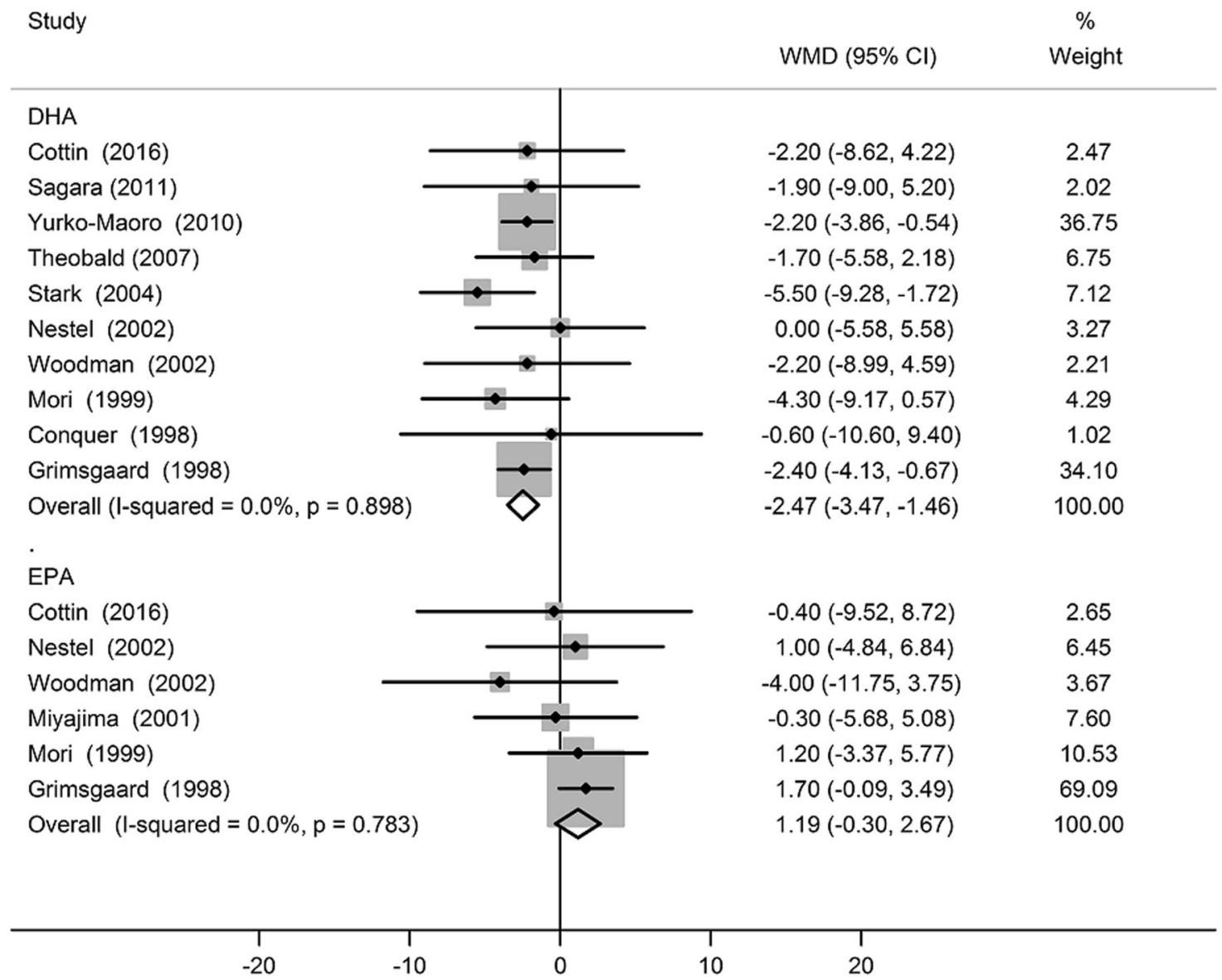

Fig. 3 Forest plot of the change in heart rate resulting from DHA and EPA supplementations

of DHA and EPA (i.e., fish oil), and more importantly, the proportion of EPA and DHA in n-3 LCPUFA supplements varied among trials. An animal study by McLennan et al. $[33,75]$ showing that DHA but not EPA prevented ischemia-induced cardiac arrhythmia in rats. Moreover, despite the fact that animals were given fish oil in which EPA is the dominant component, DHA appeared as the major $n-3$ LCPUFAs to be incorporated into myocardial membranes [76]. To date, only limited trials have examined the separate effects of DHA and EPA, with most studies showed that DHA but not EPA reduced HR [30, 31, 33-36, 40, 45, 54, 56]. Concordantly, a cross-sectional study in European men reported that DHA content of erythrocyte, but not EPA and other fatty acids, was inversely associated with HR; however, the association was slightly attenuated after further adjustment [71]. Furthermore, the inverse association between dietary fish intake and HR in observational studies [71-73] could possibly due to higher DHA content in some fish [77]. While in our general analysis, $n$ -3 LCPUFA caused HR reduction, in our subgroup analysis, DHA but not EPA reduced HR. This may be partially explained by a greater blood pressure-lowing effect of EPA than DHA ( -4.61 vs. $-1.27 \mathrm{~mm} \mathrm{Hg}$ in systolic blood pressure) as shown by a meta-analysis on hypertension treatment with omega-3 [78]. The pronounced blood pressure reduction by EPA can activate baroreceptor reflex [79, 80], thereby offsetting the HR-slowing effect of EPA if there is any.

This meta-analysis has several limitations that are worth mentioning. First, moderate degree of heterogeneity was observed across the included trials. Therefore, the findings from this meta-analysis should be interpreted with caution. Given that most of the trials showed a clear pattern towards the reduction of $\mathrm{HR}$, the observed heterogeneity across studies was potentially due to the difference in statistical significance between trials rather than due to the difference in direction of the effect size. Second, the characteristics of participants and trials varied widely across trials, and this can lead to underestimation or overestimation of the true intervention effect. However, the predefined subgroup and sensitivity analyses showed that the characteristics of participants and trials did not affect the overall effect size. Third, the effect of individual $n-3$ LCPUFAs on HR was inconclusive because these findings were based on the 
limited evidence from RCTs. Despite these limitations, this present meta-analysis can have valuable public health and clinical implications for incorporation of $n-3$ LCPUFA supplementation as a lifestyle modification for reducing allcause mortality among general populations [81], and for reducing the risk of sudden cardiac death, particularly in those who do not consume enough fatty fish on a regular basis.

\section{Conclusions}

The present meta-analysis provides strong and updated clinical evidence demonstrating the effect of heart rate reduction by $n-3$ LCPUFA supplementation. In analyzing trials with DHA or EPA alone, our study demonstrates that DHA rather than EPA is more ascribable to such chronotropic effect. Future investigations may evaluate whether heart rate reduction with $n-3$ LCPUFAs in general and with DHA in specific is associated with improved outcomes in clinical patients or with better health profile of the public.

\section{Acknowledgements}

Author contributions $\mathrm{KH}, \mathrm{L}-\mathrm{QQ}$ and $\mathrm{WZ}$ designed the research. $\mathrm{KH}$ and JY performed the literature search, data extraction, and quality assessment. $\mathrm{KH}$ performed the data analyses and wrote the paper. $\mathrm{ZZ}$ and G-CC assisted with the literature search and selection. KH, WZ, ME, and L-QQ had primary responsibility for the final content. All authors read and approved the final manuscript.

\section{Compliance with ethical standards}

Conflict of interest ME and WZ are presently employed by DSM, a manufacture of omega-3 fatty acids. The other authors declare that they have no conflict of interest.

Open Access This article is licensed under a Creative Commons Attribution 4.0 International License, which permits use, sharing, adaptation, distribution and reproduction in any medium or format, as long as you give appropriate credit to the original author(s) and the source, provide a link to the Creative Commons license, and indicate if changes were made. The images or other third party material in this article are included in the article's Creative Commons license, unless indicated otherwise in a credit line to the material. If material is not included in the article's Creative Commons license and your intended use is not permitted by statutory regulation or exceeds the permitted use, you will need to obtain permission directly from the copyright holder. To view a copy of this license, visit http://creativecommons. org/licenses/by/4.0/.

\section{References}

1. Kris-Etherton PM, Harris WS, Appel LJ, American Heart Association. Nutrition Committee. Fish consumption, fish oil, omega-3 fatty acids, and cardiovascular disease. Circulation. 2002;106:2747-57.

2. Siscovick DS, Barringer TA, Fretts AM, Wu JH, Lichtenstein AH, Costello RB, et al. Omega-3 polyunsaturated fatty acid (fish oil) supplementation and the prevention of clinical cardiovascular disease: a science advisory from the American Heart Association. Circulation. 2017;135:e867-884.

3. Albert CM, Hennekens CH, O'Donnell CJ, Ajani UA, Carey VJ, Willett WC, et al. Fish consumption and risk of sudden cardiac death. JAMA. 1998;279:23-28.

4. Albert CM, Campos H, Stampfer MJ, Ridker PM, Manson JE, Willett WC, et al. Blood levels of long-chain n-3 fatty acids and the risk of sudden death. N Engl J Med. 2002;346:1113-8.

5. Burr ML, Fehily AM, Gilbert JF, Rogers S, Holliday RM, Sweetnam PM, et al. Effects of changes in fat, fish, and fibre intakes on death and myocardial reinfarction: Diet and Reinfarction Trial (DART). Lancet. 1989;2:757-61.

6. GISSI-Prevenzione. Dietary supplementation with n-3 polyunsaturated fatty acids and vitamin $\mathrm{E}$ after myocardial infarction: results of the GISSI-Prevenzione trial. Gruppo Italiano per lo Studio della Sopravvivenza nell'Infarto miocardico. Lancet. 1999;354:447-55.

7. Marchioli R, Barzi F, Bomba E, Chieffo C, Di Gregorio D, Di Mascio R, et al. Early protection against sudden death by $n-3$ polyunsaturated fatty acids after myocardial infarction: timecourse analysis of the results of the Gruppo Italiano per lo Studio della Sopravvivenza nell'Infarto Miocardico (GISSI)-Prevenzione. Circulation. 2002;105:1897-903.

8. Kang JX. Reduction of heart rate by omega-3 fatty acids and the potential underlying mechanisms. Front Physiol. 2012;3:416.

9. Kannel WB, Kannel C, Paffenbarger RS Jr, Cupples LA. Heart rate and cardiovascular mortality: the Framingham Study. Am Heart J. 1987;113:1489-94.

10. Wannamethee G, Shaper AG, Macfarlane PW, Walker M. Risk factors for sudden cardiac death in middle-aged British men. Circulation. 1995;91:1749-56.

11. Shaper AG, Wannamethee G, Macfarlane PW, Walker M. Heart rate, ischaemic heart disease, and sudden cardiac death in middleaged British men. Br Heart J. 1993;70:49-55.

12. Zhang GQ, Zhang W. Heart rate, lifespan, and mortality risk. Ageing Res Rev. 2009;8:52-60.

13. Mehta JL, Lopez LM, Lawson D, Wargovich TJ, Williams LL. Dietary supplementation with omega-3 polyunsaturated fatty acids in patients with stable coronary heart disease: effects on indices of platelet and neutrophil function and exercise performance. Am J Med. 1988;84:45-52.

14. Mills DE, Prkachin KM, Harvey KA, Ward RP. Dietary fatty acid supplementation alters stress reactivity and performance in man. $\mathrm{J}$ Hum Hypertens. 1989;3:111-6.

15. Vacek JL, Harris WS, Haffey K. Short-term effects of omega-3 fatty acids on exercise stress test parameters, angina and lipoproteins. Biomed Pharmacother. 1989;43:375-9.

16. Levinson PD, Iosiphidis AH, Saritelli AL, Herbert PN, Steiner M. Effects of n-3 fatty acids in essential hypertension. Am J Hypertens. 1990;3:754-60.

17. Mills DE, Mah M, Ward RP, Morris BL, Floras JS. Alteration of baroreflex control of forearm vascular resistance by dietary fatty acids. Am J Physiol. 1990;259:R1164-1171.

18. Solomon SA, Cartwright I, Pockley G, Greaves M, Preston FE, Ramsay LE, et al. A placebo-controlled, double-blind study of eicosapentaenoic acid-rich fish oil in patients with stable angina pectoris. Curr Med Res Opin. 1990;12:1-11.

19. Wing LM, Nestel PJ, Chalmers JP, Rouse I, West MJ, Bune AJ, et al. Lack of effect of fish oil supplementation on blood pressure in treated hypertensives. J Hypertens. 1990;8:339-43.

20. Bairati I, Roy L, Meyer F. Effects of a fish oil supplement on blood pressure and serum lipids in patients treated for coronary artery disease. Can J Cardiol. 1992;8:41-46. 
21. Deslypere JP. Influence of supplementation with N-3 fatty acids on different coronary risk factors in men: a placebo controlled study. Verh K Acad Geneeskd Belg. 1992;54:189-216.

22. Landmark K, Thaulow E, Hysing J, Mundal HH, Eritsland J, Hjermann I. Effects of fish oil, nifedipine and their combination on blood pressure and lipids in primary hypertension. J Hum Hypertens. 1993;7:25-32.

23. Vandongen R, Mori TA, Burke V, Beilin LJ, Morris J, Ritchie J. Effects on blood pressure of omega 3 fats in subjects at increased risk of cardiovascular disease. Hypertension. 1993;22:371-9.

24. Leaf A, Jorgensen MB, Jacobs AK, Cote G, Schoenfeld DA, Scheer J, et al. Do fish oils prevent restenosis after coronary angioplasty? Circulation. 1994;90:2248-57.

25. McVeigh GE, Brennan GM, Cohn JN, Finkelstein SM, Hayes RJ, Johnston GD. Fish oil improves arterial compliance in noninsulin-dependent diabetes mellitus. Arterioscler Thromb. 1994;14:1425-9.

26. Toft I, Bonaa KH, Ingebretsen OC, Nordoy A, Jenssen T. Effects of n-3 polyunsaturated fatty acids on glucose homeostasis and blood pressure in essential hypertension: a randomized, controlled trial. Ann Intern Med. 1995;123:911-8.

27. Christensen JH, Gustenhoff P, Korup E, Aarøe J, Toft E, Møller J, et al. Effect of fish oil on heart rate variability in survivors of myocardial infarction: a double blind randomised controlled trial. BMJ. 1996;312:677-8.

28. Gray DR, Gozzip CG, Eastham JH, Kashyap ML. Fish oil as an adjuvant in the treatment of hypertension. Pharmacotherapy. 1996;16:295-300.

29. Christensen JH, Aaroe J, Knudsen N, Dideriksen K, Kornerup HJ, Dyerberg $J$, et al. Heart rate variability and n-3 fatty acids in patients with chronic renal failure: a pilot study. Clin Nephrol. 1998;49:102-6.

30. Conquer JA, Holub BJ. Effect of supplementation with different doses of DHA on the levels of circulating DHA as non-esterified fatty acid in subjects of Asian Indian background. J Lipid Res. 1998;39:286-92.

31. Grimsgaard S, Bonaa KH, Hansen JB, Myhre ES. Effects of highly purified eicosapentaenoic acid and docosahexaenoic acid on hemodynamics in humans. Am J Clin Nutr. 1998;68:52-59.

32. Christensen JH, Christensen MS, Dyerberg J, Schmidt EB. Heart rate variability and fatty acid content of blood cell membranes: a dose response study with $\mathrm{n}-3$ fatty acids. Am J Clin Nutr. 1999;70:331-7.

33. Mori TA, Bao DQ, Burke V, Puddey IB, Beilin LJ. Docosahexaenoic acid but not eicosapentaenoic acid lowers ambulatory blood pressure and heart rate in humans. Hypertension. 1999;34:253-60.

34. Miyajima T, Tsujino T, Saito K, Yokoyama M. Effects of eicosapentaenoic acid on blood pressure, cell membrane fatty acids, and intracellular sodium concentration in essential hypertension. Hypertens Res. 2001;24:537-42.

35. Nestel P, Shige H, Pomeroy S, Cehun M, Abbey M, Raederstorff D. The n-3 fatty acids eicosapentaenoic acid and docosahexaenoic acid increase systemic arterial compliance in humans. Am J Clin Nutr. 2002;76:326-30.

36. Woodman RJ, Mori TA, Burke V, Puddey IB, Watts GF, Beilin LJ. Effects of purified eicosapentaenoic and docosahexaenoic acids on glycemic control, blood pressure, and serum lipids in type 2 diabetic patients with treated hypertension. Am J Clin Nutr. 2002;76:1007-15.

37. Geelen A, Zock PL, Swenne CA, Brouwer IA, Schouten EG, Katan MB. Effect of n-3 fatty acids on heart rate variability and baroreflex sensitivity in middle-aged subjects. Am Heart J. 2003;146:E4

38. Dyerberg J, Eskesen DC, Andersen PW, Astrup A, Buemann B, Christensen $\mathrm{JH}$, et al. Effects of trans- and n-3 unsaturated fatty acids on cardiovascular risk markers in healthy males: an 8 weeks dietary intervention study. Eur J Clin Nutr. 2004;58:1062-70.

39. Monahan KD, Wilson TE, Ray CA. Omega-3 fatty acid supplementation augments sympathetic nerve activity responses to physiological stressors in humans. Hypertension. 2004;44:732-8.

40. Stark KD, Holub BJ. Differential eicosapentaenoic acid elevations and altered cardiovascular disease risk factor responses after supplementation with docosahexaenoic acid in postmenopausal women receiving and not receiving hormone replacement therapy. Am J Clin Nutr. 2004;79:765-73.

41. Geelen A, Brouwer IA, Schouten EG, Maan AC, Katan MB, Zock PL. Effects of n-3 fatty acids from fish on premature ventricular complexes and heart rate in humans. Am J Clin Nutr. 2005;81:416-20.

42. O'Keefe JH, Abulssa H, Sastre A, Steinhaus D, Harris W. AHArecommended intakes of omega- 3 fatty acids improve indicators of cardiac autonomic tone but not lipids or inflammatory markers. Presented at: American College of Cardiology Scientific Session; March 6-9, 2005; Orlando, FL. Abstract.

43. Harris WS, Gonzales M, Laney N, Sastre A, Borkon AM. Effects of omega-3 fatty acids on heart rate in cardiac transplant recipients. Am J Cardiol. 2006;98:1393-5.

44. Shah AP, Ichiuji AM, Han JK, Traina M, El-Bialy A, Meymandi SK, et al. Cardiovascular and endothelial effects of fish oil supplementation in healthy volunteers. J Cardiovasc Pharmacol Ther. 2007;12:213-9.

45. Theobald HE, Goodall AH, Sattar N, Talbot DC, Chowienczyk PJ, Sanders TA. Low-dose docosahexaenoic acid lowers diastolic blood pressure in middle-aged men and women. $J$ Nutr. 2007;137:973-8.

46. DeGiorgio CM, Miller P, Meymandi S, Gornbein JA. n-3 fatty acids (fish oil) for epilepsy, cardiac risk factors, and risk of SUDEP: clues from a pilot, double-blind, exploratory study. Epilepsy Behav. 2008;13:681-4.

47. Ninio DM, Hill AM, Howe PR, Buckley JD, Saint DA. Docosahexaenoic acid-rich fish oil improves heart rate variability and heart rate responses to exercise in overweight adults. Br J Nutr. 2008;100:1097-103.

48. Peoples GE, McLennan PL, Howe PR, Groeller H. Fish oil reduces heart rate and oxygen consumption during exercise. $\mathrm{J}$ Cardiovasc Pharmacol. 2008;52:540-7.

49. Walser B, Stebbins CL. Omega-3 fatty acid supplementation enhances stroke volume and cardiac output during dynamic exercise. Eur J Appl Physiol. 2008;104:455-61.

50. Buckley JD, Burgess S, Murphy KJ, Howe PR. DHA-rich fish oil lowers heart rate during submaximal exercise in elite Australian Rules footballers. J Sci Med Sport. 2009;12:503-7.

51. Nodari S, Metra M, Milesi G, Manerba A, Cesana BM, Gheorghiade $M$, et al. The role of $n-3$ PUFAs in preventing the arrhythmic risk in patients with idiopathic dilated cardiomyopathy. Cardiovasc Drugs Ther. 2009;23:5-15.

52. Carney RM, Freedland KE, Stein PK, Steinmeyer BC, Harris WS, Rubin EH, et al. Effect of omega-3 fatty acids on heart rate variability in depressed patients with coronary heart disease. Psychosom Med. 2010;72:748-54.

53. Sjoberg NJ, Milte CM, Buckley JD, Howe PR, Coates AM, Saint DA. Dose-dependent increases in heart rate variability and arterial compliance in overweight and obese adults with DHA-rich fish oil supplementation. Br J Nutr. 2010;103:243-8.

54. Yurko-Mauro K, McCarthy D, Rom D, Nelson EB, Ryan AS, Blackwell A, et al. Beneficial effects of docosahexaenoic acid on cognition in age-related cognitive decline. Alzheimers Dement. 2010;6:456-64.

55. Kim SH, Kim MK, Lee HY, Kang HJ, Kim YJ, Kim HS. Prospective randomized comparison between omega-3 fatty acid 
supplements plus simvastatin versus simvastatin alone in Korean patients with mixed dyslipidemia: lipoprotein profiles and heart rate variability. Eur J Clin Nutr. 2011;65:110-6.

56. Sagara M, Njelekela $M$, Teramoto $T$, Taguchi $T$, Mori $M$, Armitage L, et al. Effects of docosahexaenoic Acid supplementation on blood pressure, heart rate, and serum lipids in Scottish men with hypertension and hypercholesterolemia. Int $\mathbf{J}$ Hypertens. 2011;2011:809198.

57. Noreen EE, Brandauer J. The effects of supplemental fish oil on blood pressure and morning cortisol in normotensive adults: a pilot study. J Complement Integr Med. 2012;9:1

58. Carter JR, Schwartz CE, Yang H, Joyner MJ. Fish oil and neurovascular reactivity to mental stress in humans. Am J Physiol Regul Integr Comp Physiol. 2013;304:R523-530.

59. Hansen AL, Olson G, Dahl L, Thornton D, Grung B, Graff IE, et al. Reduced anxiety in forensic inpatients after a long-term intervention with Atlantic salmon. Nutrients. 2014;6:5405-18.

60. Logan SL, Spriet LL. Omega-3 fatty acid supplementation for 12 weeks increases resting and exercise metabolic rate in healthy community-dwelling older females. PLoS ONE. 2015;10: e0144828.

61. Cottin SC, Alsaleh A, Sanders TA, Hall WL. Lack of effect of supplementation with EPA or DHA on platelet-monocyte aggregates and vascular function in healthy men. Nutr Metab Cardiovasc Dis. 2016;26:743-51.

62. Kristensen S, Schmidt EB, Schlemmer A, Rasmussen C, Lindgreen E, Johansen MB, et al. The effect of marine n-3 polyunsaturated fatty acids on cardiac autonomic and hemodynamic function in patients with psoriatic arthritis: a randomised, double-blind, placebo-controlled trial. Lipids Health Dis. 2016;15:216.

63. Matsumura K, Noguchi H, Nishi D, Hamazaki K, Hamazaki T, Matsuoka YJ. Effects of omega-3 polyunsaturated fatty acids on psychophysiological symptoms of post-traumatic stress disorder in accident survivors: A randomized, double-blind, placebocontrolled trial. J Affect Disord. 2016;224:27-31.

64. Mozaffarian D, Geelen A, Brouwer IA, Geleijnse JM, Zock PL, Katan MB. Effect of fish oil on heart rate in humans: a metaanalysis of randomized controlled trials. Circulation. 2005;112: 1945-52.

65. Moher D, Liberati A, Tetzlaff J, Altman DG, PRISMA Group. Preferred reporting items for systematic reviews and meta-analyses: the PRISMA statement. PLoS Med. 2009;6: e1000097.

66. Higgins J, Green S Cochrane Handbook for Systematic Reviews of Interventions Version 5.1.0. The Cochrane Collaboration. Available online: http://handbook.cochrane.org/ (accessed on 5 May 2017).
67. Follmann D, Elliott P, Suh I, Cutler J. Variance imputation for overviews of clinical trials with continuous response. J Clin Epidemiol. 1992;45:769-73.

68. Egger M, Davey Smith G, Schneider M, Minder C. Bias in metaanalysis detected by a simple, graphical test. BMJ. 1997;315: 629-34.

69. Duval S, Tweedie R. Trim and fill: a simple funnel-plot-based method of testing and adjusting for publication bias in metaanalysis. Biometrics. 2000;56:455-63.

70. DerSimonian R, Laird N. Meta-analysis in clinical trials. Control Clin Trials. 1986;7:177-88.

71. Dallongeville J, Yarnell J, Ducimetière P, Arveiler D, Ferrières J, Montaye M, et al. Fish consumption is associated with lower heart rates. Circulation. 2003;108:820-5.

72. Mozaffarian D, Gottdiener JS, Siscovick DS. Intake of tuna or other broiled or baked fish versus fried fish and cardiac structure, function, and hemodynamics. Am J Cardiol. 2006;97:216-22.

73. Mozaffarian D, Prineas RJ, Stein PK, Siscovick DS. Dietary fish and n-3 fatty acid intake and cardiac electrocardiographic parameters in humans. J Am Coll Cardiol. 2006;48:478-84.

74. Jiang X, Liu X, Wu S, Zhang GQ, Peng M, Wu Y, et al. Metabolic syndrome is associated with and predicted by resting heart rate: a cross-sectional and longitudinal study. Heart. 2015;101:44-49.

75. McLennan P, Howe P, Abeywardena M, Muggli R, Raederstorff $\mathrm{D}$, Mano $\mathrm{M}$, et al. The cardiovascular protective role of docosahexaenoic acid. Eur J Pharmacol. 1996;300:83-89.

76. Pepe S, McLennan PL. Dietary fish oil confers direct antiarrhythmic properties on the myocardium of rats. J Nutr. 1996;126: 34-42.

77. Abdukeyum GG, Owen AJ, McLennan PL. Dietary (n-3) longchain polyunsaturated fatty acids inhibit ischemia and reperfusion arrhythmias and infarction in rat heart not enhanced by ischemic preconditioning. J Nutr. 2008;138:1902-9.

78. Miller PE, Van Elswyk M, Alexander DD. Long-chain omega-3 fatty acids eicosapentaenoic acid and docosahexaenoic acid and blood pressure: a meta-analysis of randomized controlled trials. Am J Hypertens. 2014;27:885-96.

79. Zhang W. Can we use calcium antagonist better in antihypertensive therapy? Circadian consideration. Pharmacol Res. 1996;34:187-91.

80. Zhang W, Wang Z. Resetting baroreceptors to a lower arterial pressure level by enalapril avoids baroreflex mediated activation of sympathetic nervous system by nifedipine. Life Sci. 2001;68: 2769-79.

81. Chen GC, Yang J, Eggersdorfer M, Zhang W, Qin LQ. N-3 longchain polyunsaturated fatty acids and risk of all-cause mortality among general populations: a meta-analysis. Sci Rep. 2016;6: 28165. 